\section{Check for updates}

Cite this: RSC Adv., 2019, 9, 27475

DOI: $10.1039 / \mathrm{c} 9 \mathrm{ra90064k}$

www.rsc.org/advances

\title{
Correction: Silica cubosomes templated by a star polymer
}

\author{
Congcong Cui, ${ }^{\mathrm{a}} \mathrm{Lu} \mathrm{Han}^{\star \mathrm{a}}$ and Shunai Che ${ }^{\mathrm{ab}}$
}

Correction for 'Silica cubosomes templated by a star polymer' by Congcong Cui et al., RSC Adv., 2019, 9, 6118-6124.

The authors wish to report extra characterisation data to provide further evidence for the synthesis of the $\mathrm{AB}_{2}$ star polymer reported in the original article.

The authors have added additional ${ }^{1} \mathrm{H}$ NMR (Fig. S8) and MALDI-TOF MS (Fig. S9) spectra for all synthesis steps of the reaction to support the polymer synthesis. The ${ }^{1} \mathrm{H}$ NMR spectra show the appearance and disappearance of two of the characteristic peaks for 4methylphenyl in the reactions to synthesise PEG-N-OH peak of the macroinitiator (PEG-N-Br 2 ) is also observed (marked in the blue box, Fig. S8). The MALDI-TOF MS spectrum of the product of each reaction shows a set of peaks with a spacing of $44 \mathrm{~m} / z$ (corresponding to the PEG repeating unit, $-\mathrm{CH}_{2}-\mathrm{CH}_{2}-\mathrm{O}-$ ). The main peak position changes as the terminal group changes. The absolute molecular weight of each product obtained through MALDI-TOF MS matches well with the calculated molecular weight.

The electronic supplementary information (ESI) of the original article has been updated to reflect these changes.

In addition, the authors regret that the signal for the $\mathrm{CH}-\mathrm{Br}$ group in the ${ }^{1} \mathrm{H}$ NMR spectrum, shown in Fig. 1 of the original article, was incorrectly assigned. The signal should have been assigned to the broad peak at around $4.5 \mathrm{ppm}$. Due to the small number of end groups compared to the polymer chain, the signals of the end groups are very weak and difficult to identify. The correct version of Fig. 1 is shown below.

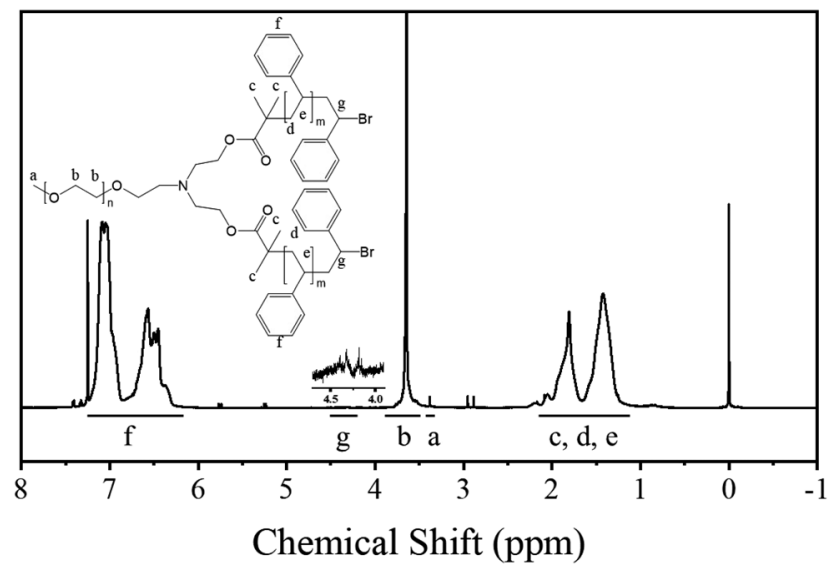

Fig. $1{ }^{1} \mathrm{H}$ NMR spectrum of the polymer.

The Royal Society of Chemistry apologises for these errors and any consequent inconvenience to authors and readers. 